\title{
O LUGAR DAS IDEIAS LIBERAIS NAS MEMÓRIAS PÓSTUMAS DE BRÁS CUBAS
}

\section{ELVIS PAULO COUTO}

Universidade Estadual Paulista "Júlio de Mesquita Filho" Araraquara, São Paulo, Brasil

Resumo: Em seu conhecido livro Um mestre na periferia do capitalismo, Roberto Schwarz mostra que o princípio formal predominante do romance Memórias póstumas de Brás Cubas, de Machado de Assis - a volubilidade do narrador em primeira pessoa -, foi criado com vistas a expor crítica e ironicamente a aclimatação do liberalismo no Brasil. Este artigo, além de questionar a implicação sociológica desse argumento, visa a discutir a representação das ideias liberais no romance machadiano sob a perspectiva que salienta o triunfo do liberalismo no plano da imaginação literária.

Palavras-chave: Machado de Assis; Memórias póstumas de Brás Cubas; liberalismo.

\section{THE PLACE OF LIBERAL IDEAS IN THE POSTHUMOUS MEMOIRS OF BRÁS CUBAS}

Abstract: In his well-known book, A Master on the Periphery of Capitalism, Roberto Schwarz shows that the predominant formal principle, the volubility of the firstperson narrator, in Machado de Assis's The Posthumous Memoirs of Brás Cubas was created to critically and ironically expose how Brazil was acclimating to liberalism. In addition to questioning the sociological implication of this argument, this paper aims to discuss the representation of liberal ideas in Machado's novel from the perspective that underlines the triumph of liberalism in the literary imagination.

Keywords: Machado de Assis; The Posthumous Memoirs of Brás Cubas; liberalism.

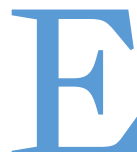

m 1958, um grupo de intelectuais uspianos de esquerda reuniu-se para estudar O capital, de Karl Marx. No artigo "Um seminário de Marx", Roberto Schwarz (1998) narra essa experiência, da qual ele participou, e evidencia o principal objetivo dela, qual seja, desenvolver teses 
dialéticas que culminassem na seguinte práxis: a superação do subdesenvolvimento brasileiro. O marxismo clássico foi apenas um ponto de partida para Schwarz, pois seu interesse voltava-se menos aos aspectos econômicos do capitalismo do que aos aspectos culturais. Na verdade, no limiar do decênio de 1960, ele já estava alinhado à vocação mais íntima do marxismo ocidental: a Kulturkritik.

Schwarz norteia-se pelo programa filosófico do marxismo no século XX arquitetado com rigor por György Lukács em História e consciência de classe de 1923. Nessa obra, Lukács (2003) mostra que a doutrina políticoeconômica de Marx como um todo não é mais importante do que o método por que ela é exposta: a dialética de Hegel. Na Fenomenologia do espírito de 1807, Hegel (2014) assevera que a realidade imediata e finita do ser só pode ser conhecida dialeticamente, isto é, como parte da totalidade histórica. Se se confia somente na unidade contraditória do ser, obsta-se a aquisição de uma visão de conjunto, a única que, de acordo com a lógica hegeliana, se abre ao real. A crítica dialética da cultura, primeiramente, tem de descobrir a contradição interna do objeto a ser investigado, ou seja, a relação contraditória que constitui o seu ser.

Por intermédio da dialética, conclui Lukács (2003), Marx verificou que a realidade histórica não é um processo exclusivamente determinado pelo Espírito, como acreditava Hegel, mas cognoscível e, por isso mesmo, passível de mudança. Na era burguesa, somente pode-se ter consciência da totalidade do processo histórico com uma teoria que coloque em evidência: 1) a reificação, uma forma de alienação que consiste em reduzir o homem à mercadoria, ou seja, em converter as relações interpessoais em relações entre coisas; 2) as antinomias inerentes à estrutura mental da burguesia e resultantes da legitimação, no plano superestrutural, de seus interesses de classe (ideologia). Para Lukács (2003), o proletariado é a única classe capaz de adquirir a visão do todo, descortinando a natureza nociva da reificação e da ideologia, pois a penúria que o assola lhe permite livrar-se daquelas antinomias próprias a quem detém o poder econômico.

Schwarz, inspirando-se no planejamento filosófico lukacsiano, notou, sapientemente, que a periferia do capitalismo, em escala global, é o locus privilegiado para que se manifeste essa compreensão histórica. Foi assim que concretizou a dupla investigação que o tornaria herdeiro do marxismo ocidental: 1) devido à condição de subdesenvolvimento do Brasil, divisou com mais nitidez, por meio do modo de exposição dialético, as contradições do capitalismo, conforme já salientou Bernardo Ricupero (2008, p. 65; 2013, p. 
540) e Sergio Paulo Rouanet (1991, p. 183); 2) executou a Ideologiekritik, isto é, a forma mais atualizada do marxismo, liberta do determinismo econômico e exercida por frankfurtianos como Herbert Marcuse e Theodor W. Adorno.

Schwarz não teria desenvolvido ex nihilo a Ideologiekritik, posto que a teria encontrado no assim chamado primeiro romance moderno brasileiro, que foi publicado, em 1880, por Machado de Assis, em folhetim, com o título Memórias póstumas de Brás Cubas. Ao publicar, em 1977, Ao vencedor as batatas, Schwarz (2000a) sustém, sobretudo no ensaio que encabeça o livro "As ideias fora do lugar" -, uma explicação do atraso brasileiro: com a Independência, as classes dirigentes brasileiras não buscaram formas de superar o retrocesso inerente à herança colonial, coadunando modo de produção escravista e cooptação de clientes com ideias burguesas, liberais e progressistas em voga na Europa, tais como: defesa do trabalho livre e das instituições burocráticas, igualdade perante a lei, liberdade pessoal, ciência econômica etc. Ao mesmo tempo que era impraticável, o liberalismo tinha a função de dar embasamento intelectual às instituições do novo Estado e, sardonicamente, justificar com corolários iluministas anglo-franceses a manutenção de práticas atrasadas, isto é, a preservação dos interesses da classe dominante. As ideias liberais seriam, portanto, ideologia, não de primeiro grau, como na Europa - encobrindo a exploração do trabalho -, mas de segundo - escamoteando o escravismo e o clientelismo.

Em Um mestre na periferia do capitalismo, publicado em 1990, Schwarz (2000b) sustenta a tese de que Machado teria criado a personagem central das Memórias póstumas a partir do desajuste risível entre o ideário burguês liberal-iluminista e as práticas de exploração escravagista e clientelista executadas por grupos oligárquico-rentistas. Brás Cubas, ao evocar, reiteradamente, o padrão ético burguês (norma) e descumpri-lo logo em seguida com discursos justificadores do paternalismo e da arbitrariedade da classe proprietária (infração), estaria comportando-se voluvelmente. Logo, a volubilidade seria, a um só tempo, um dado estrutural da sociedade brasileira e um princípio formal do romance. A essência da tese schwarziana é a seguinte: a técnica narrativa escolhida por Machado - o narrador volúvel que ora alinha a sua dicção ao liberalismo, ora a faz concordar com a manutenção da herança colonial, potencializando esse efeito de contradição com a combinação estapafúrdia de tópicos e estilos variados - serviria ao objetivo de desmascarar a veleidade de Brás Cubas, o representante da elite oitocentista brasileira. Assim, o bruxo do Cosme Velho, segundo Schwarz (1999, p. 223), "por estratagema adota o ponto de vista do inimigo, apropria-se dele, 
transforma em procedimento narrativo de todos os instantes a conduta de classe arbitrária e irresponsável." Schwarz (2011; 2012, p. 17-18) chega a afirmar que esse pendor literário para mettre en scène o comportamento classista é um depoimento de esquerda propulsionador da luta contra o atraso do Brasil.

Paulo Eduardo Arantes (1992), o principal comentador da obra Um mestre na periferia do capitalismo, mostra que Schwarz descobriu no Brás Cubas uma crítica cultural oposicionista e confrontadora, um impulso anticapitalista. Machado teria evidenciado, com o seu magnus opum, que as garantias liberais de igualdade, liberdade e universalidade propaladas pela burguesia europeia não se realizam de fato, adquirindo, portanto, a função de ideologia. Arantes (2004, p. 282) apresenta Machado como um precursor da Ideologiekritik marxista: "[...] nós temos a possibilidade, através de Machado, de entender o que está acontecendo na Europa. E o que estava acontecendo na Europa, na época de Machado, era a derrocada da civilização liberal burguesa." Ainda de acordo com Arantes (2004, p. 282), Machado seria um antiliberal, pois, como "era radicalmente crítico em relação ao capitalismo", teria desqualificado adrede o "programa liberal burguês", revelando que ele "estava contaminado desde a raiz" e que não passava de formalismo. Essa aversão ao liberalismo estaria ironicamente condensada no Humanitismo exposto por Quincas Borba ao Brás Cubas. Para Arantes (2004, p. 282), o sistema filosófico de Humanitas seria "uma salada grotesca da fraseologia burguesa mais avançada para sacramentar barbaridades cá [Brasil] e lá [Europa]."

Vale salientar que a leitura que Schwarz faz do Brás Cubas norteia-se, essencialmente, pelas seguintes teorias literárias: 1) a Teoria do romance, publicada por Lukács (2000) em 1916, onde o filósofo húngaro apresenta uma concepção de herói romanesco que foi resgatada por Schwarz (2000b) em sua caracterização da volubilidade do Brás Cubas: a história da personagem central do romance moderno é a busca de valores autênticos no mundo racionalista e burguês assolado pelo esvaziamento mitológico, religioso e axiológico; 2) o ensaio "O romance como epopeia burguesa" de 1935, em que Lukács (1999) enfatiza que o romance reflete a ética burguesa e as contradições da sociedade capitalista - exatamente o programa crítico de Schwarz (2000b); 3) a Estética de 1957 e a ensaística em geral sobre o realismo (sobretudo, "Narrar ou descrever" e "A polêmica entre Balzac e Stendhal"), nas quais Lukács (1968a, 1968b, 1970) instaura a categoria da tipicidade, uma espécie de capacidade hegeliana que certos escritores têm para criar 
personagens e situações que transmitam experiências ao mesmo tempo particulares e mediadas pelo universal; em geral, ser típico, para Lukács, é transcender o imediatismo contraditório da realidade histórica e sintetizar discursivamente as tendências conflitantes do espírito do tempo, a fim de que apareçam, preferencialmente - como ocorreria nas Memórias póstumas segundo Schwarz (2000b) -, as antinomias da sociedade burguesa; 4) duas ideias estéticas centrais no pensamento adorniano: a primeira propõe que a função da arte é protestar contra a reificação (ADORNO, 2003a, p. 22) e a segunda que as "obras de arte [...] têm sua grandeza unicamente em deixarem falar aquilo que a ideologia esconde." (ADORNO, 2003b, p. 68). Desses pressupostos estéticos de Adorno, erigiu-se a avidez schwarziana de buscar na literatura de Machado a demonstração da falsidade da ideologia.

Por um lado, Schwarz parte, para formular a sua tese, do núcleo teórico do marxismo ocidental; por outro lado, retoma e modifica o que considera mais preeminente na fortuna crítica machadiana.

A descoberta do princípio formal da volubilidade é o ponto mais alto da crítica das Memórias póstumas, posto que é possível, por meio dele, depreender a instabilidade e o capricho do narrador, seu discurso bruxuleante. O mérito da definição exata do comportamento volúvel da personagem central do romance é de Augusto Meyer (1958), que o analisa com foco, sobretudo, na melancolia e no ceticismo dele decorrentes. Além de Meyer, importantes críticos dedicaram-se à análise psicológica do humor melancólico e do pessimismo que beira o niilismo: Alcides Maya (1942), Barreto Filho (1947), Eugênio Gomes (1958) e Lúcia Miguel Pereira (1988).

Schwarz (2000b), objetivando fundir o direcionamento estilísticoformal com o sócio-histórico, sem incorrer no sociologismo ou no exame exclusivamente técnico dos aspectos formais, resgata o conceito de volubilidade de Meyer, enxergando nele, em vez de inclinação psicológica que considera falsa -, ideologia (ideias liberal-progressistas que são infringidas pelo trabalho compulsório e pela dominação pessoal direta).

Isso posto, acreditamos que os fundamentos da crítica de Schwarz ao Brás Cubas significam um avanço considerável no nicho político da fortuna crítica machadiana, mas grande parte das conclusões a que chegam precisa ser revista, pois está em desacordo com a objetividade da natureza formal e ideológica da obra.

Comecemos pelo forte argumento de Schwarz (2000a, 2000b), que perpassa os seus dois livros sobre Machado, segundo o qual as ideias liberais, por estarem desajustadas, produzem cômica aberração, a qual foi 
transformada em forma literária - a dicção volúvel do narrador das Memórias póstumas.

Para contestar esse ponto de vista, Maria Sylvia de Carvalho Franco (1976) e Alfredo Bosi (1996) mostram que a igualdade, premissa constitucional do ideário liberal-burguês, era, realmente, apenas uma formalidade no Império brasileiro; todavia, tinha a função de manter a aparência de que as relações entre proprietários e clientes (os prestadores de favor e serviços) eram simétricas. Almejando comprovar que as ideias estavam no seu devido lugar, os autores afirmam o que não foi em nenhum momento negado por Schwarz: ${ }^{1}$ o postulado abstrato de que os homens são iguais visa a legitimar a exploração promovida por latifundiários. Portanto, as análises de Franco e Bosi, bon gré, mal gré, endossam a argumentação desenvolvida em Um mestre na periferia do capitalismo.

Na obra de Schwarz (2000b), a noção de que o narrador foi construído com vistas a expor crítica e ironicamente a excentricidade que envergonharia o Brasil vis-à-vis o Ocidente, isto é, o desconcerto entre o ideário moderno e as instituições atrasadas, foi fragilizada por Sergio Paulo Rouanet (1991, p. 184185), que mostra que esse desajuste não faz do Brasil um caso particular e estranho. De acordo com o autor, na Europa do século XVIII, ideias burguesas coexistiam com relações sociais de tipo feudal; filósofos iluministas defendiam a liberdade universal, mas davam continuidade, no âmbito particular, a práticas opressivas. Nos Estados Unidos, o liberalismo conviveu com o escravismo e isso não atravancou o progresso do país. Rouanet (1991, p. 194) vai mais longe: se a volubilidade de Brás Cubas visa a captar a peculiaridade histórica do Brasil por meio da denúncia do desconcerto de que se está tratando, como explicar o fato de que os narradores volúveis em Tristram Shandy, de Laurence Sterne, em Voyage autour de ma chambre, de Xavier de Maistre, em Viagens na minha terra, de Almeida Garrett, também expõem debochada e caprichosamente a contradição entre o legado liberaliluminista e as relações sociais do Ancien Régime? Ao vincular-se a forma literária diretamente à situação histórica do Brasil, confia-se demasiadamente no poder heurístico do critério sociológico e, por consequência, perde-se a amplitude do significado que essa forma comporta.

Ao constatar no "revoltante narrador" das Memórias póstumas um dispositivo literário movido a fins tanto de denúncia da perversidade inerente à ideologia de segundo grau quanto de incitação "da luta social generalizada",

${ }^{1}$ Schwarz (2012, p. 167) afirma que a sua intenção não foi, como interpretaram erroneamente Franco e Bosi, defender a tese de que as ideias liberais, no Brasil, estavam fora de lugar, mas entender por que elas estavam fora de lugar. 
Schwarz (1987, p. 44) suplanta o relevo da forma volúvel: inspirado na ideia adorniana de que a qualidade da literatura depende de seu poder de descortínio da ideologia, ele adere à suposição de que o discurso narrativo produzido por Brás é fruto de intenção científica alinhada ao marxismo. Além disso, tendo-se em vista que, como afirma Roberto Campos (1991, p. 2), a doutrina liberal tornou-se, em meados do século XIX, vitoriosa no mundo europeu, pois fortaleceu a democracia política e contribuiu para que a Belle Époque prosperasse, se Machado estivesse demonstrando "a derrocada da civilização liberal", para usar a expressão de Paulo Arantes (2004, p. 282), teria feito um exame irracional de conjuntura. E a sua "luta contra o subdesenvolvimento", como diz Schwarz (2012, p. 17-18), ter-se-ia convertido em estímulo ao desenvolvimento do subdesenvolvimento.

A volubilidade, inicialmente identificada por Meyer (1958), é uma chave analítica profícua para o entendimento do discurso narrativo do Brás Cubas. Com efeito, há incontestável sagacidade interpretativa na ideia schwarziana de que o narrador volúvel submete ironicamente o legado liberaliluminista a seus caprichos. No entanto, diferentemente de Schwarz, pode-se ver o modo caprichoso de dispor as ideias liberais não como mimese do descompasso ideológico concernente à realidade histórica brasileira; outra perspectiva é possível: o desconjuntamento do liberalismo diz respeito à sua passagem para a forma literária.

Em oposição ao desajuste afirmado por Schwarz, poderíamos notar a acomodação do liberalismo no plano das ideias, mais propriamente, no âmbito da literatura. Baseando-se em Goethe, o crítico norte-americano Lionel Trilling (1953a, p. 5-10; 1953b, p. 268-287) mostra que os sentimentos liberais se transformam em ideias liberais e que estas, por sua vez, podem se converter em linguagem literária. Para ele, há profunda identidade entre sentimentos e ideias, assim como há uma relação estreita entre literatura e política. Política, frise-se, no sentido cultural: organização da vida em sociedade e configuração de padrões morais com foco na qualidade da vida humana. Apoiando-se, também, nos estudos de John Stuart Mill sobre Coleridge, Trilling demonstra que as tendências do liberalismo aparecem, primeiramente, nos sentimentos e na imaginação. Há uma indissociabilidade entre romance moderno e ideias porque ele lida, substancialmente, com valores, decisões, situações éticas, emoções, desejos, memória, intuição etc. No fundo, para Trilling, forma é um meio de manifestação da ideia, que, por sua vez, provém de sentimentos vivenciados em situações particulares carregadas de valores morais. 
Para Schwarz (2000b) e Arantes (1992, 2004), o liberalismo, no Brasil, não se consolidou plenamente e, na Europa, não efetivou as garantias que os seus axiomas prometem, posto que é ideologia. Em contrapartida, é lícito admitir-se que ele triunfou no terreno das ideias, no território da liberdade de espírito, na literatura brasileira. Não se almeja, aqui, propor o sucesso ou o fracasso do liberalismo no Brasil oitocentista, mas enfatizar a maneira por que ele aparece na imaginação do narrador Brás Cubas. Em síntese, trata-se de lançar luz sobre - para usar a expressão de Trilling (1953a) - a "imaginação liberal" dessa personagem.

De fato, há, em Um mestre na periferia do capitalismo - e esse livro foi o ponto de partida dos questionamentos que aqui estão sendo levantados -, uma pesquisa sobre as ideias liberais, mas elas são examinadas em sua relação contraditória com o atraso colonial (estrutura escravagista e sistema de cooptação) a fim de tornar evidente a sua aclimatação historicamente desfigurada. Schwarz tende, desse modo, ao cientificismo: o fato de Brás Cubas distorcer o legado liberal não atesta cientificamente que as elites brasileiras o faziam também. Para reconstruir a mentalidade das classes dirigentes do período monárquico, seria necessário, como diz Weber (2001, p. 122), obter "um material de observação exato" referente a "acontecimentos culturais concretos e individuais da realidade histórica".

Sob outra perspectiva, pode-se divisar a volubilidade no modo de construção do discurso narrativo como manifestação expansível do ideário liberal conduzida por uma problematização ética (e não como ideologia). Não interessa, a esse tipo de análise, o liberalismo do ponto de vista constitucional, que, segundo Merquior (1991, p. 36), é "um corpo de formulações teóricas que defendem um Estado constitucional"; tampouco a perspectiva econômica - a "economia clássica", "o ramo do conhecimento inaugurado por Adam Smith, sistematizado por David Ricardo e, ilustrado, entre outros escritores, por Mill" - contribuirá para a discussão.

A narrativa do Brás Cubas é uma tentativa de realização da liberdade, mais especificamente, da "liberdade positiva" tal como conceituada por Isaiah Berlin (2002), isto é, como poder de governar-se, como autonomia. Esse conceito de Berlin coaduna-se, de acordo com Merquior (1991, p. 30-32, grifo do autor), com a ideia liberal da Bildung, que, para Wilhelm von Humboldt, é "a preocupação humanista de formação da personalidade e aperfeiçoamento pessoal"; para Benjamin Constant e Stuart Mill, é o "desdobramento do potencial humano"; para Kant, é "autotelia ou realização pessoal"; para Hegel, 
por fim, é a "liberdade como um poder em desenvolvimento de realização pessoal."

Bosi (2006, p. 316) e Rouanet (1991, p. 190-191) acreditam que a leitura mais fidedigna das Memórias póstumas seria aquela que integrasse os principais estratos interpretativos que segmentam a fortuna crítica machadiana - o estilístico-formal, o psicológico e filosófico, o sócio-histórico e político -; contudo, estamos conscientes de que ainda é necessária uma interpretação do princípio formal da volubilidade do narrador Brás Cubas do ponto de vista das tensões políticas; mais propriamente, uma análise com foco na ideia de que a forma narrativa da volubilidade é ela mesma a fundamentação de uma reflexão ética sobre o liberalismo.

É sabido que, nas Memórias póstumas, pululam teorias, o que levou Miguel Reale (2005, p. 11) a identificar no romance a "constante teorética", entendida como "teoria da teoria", "inclinação para ir além da 'explicação do real', a fim de se elaborar, sobre essa base teórica, uma teoria de valor mais amplo e simbólico." Augusto Meyer (1958, p. 16) chamou essa "constante teorética" de "monstro cerebral, a volúpia da análise pela análise". Bastam algumas referências presentes na obra de Machado de Assis (1975) para corroborar essa tendência reflexiva: a invenção do emplasto antihipocondríaco para aliviar a melancolia da humanidade, a teoria das edições humanas, a lei da equivalência das janelas, o Humanitismo, o fenômeno do ventriloquismo cerebral, o princípio de Helvétius.

Para Trilling (1953a, p. 8-9), é na literatura que a imaginação liberal se manifesta antes de se transformar em tendência liberal; ela é, pois, o meio privilegiado para a discussão ética. Nos romances, o liberalismo aparece como valorização da liberdade de organizar a variedade e a possibilidade da ação humana. À medida que o liberalismo tende positivamente à organização racional da vida, acaba concentrando-se em demasia na formulação de teorias sobre a natureza da mente e, ao mesmo tempo, desprezando as emoções. No entanto, ao confiar exageradamente no poder do raciocínio e ao deixar de alimentar emocionalmente a imaginação, o intelecto se deteriora. Isso nos permite notar que a "constante teorética" do romance machadiano é uma crítica conservadora ao liberalismo com o intuito de estimular a reflexão sobre o exagero do racionalismo que lhe é característico.

A inclinação do romance machadiano ao desenvolvimento de teorias, filosofias e ideias fixas, que se põem "a bracejar, a pernear, a fazer as mais arrojadas cabriolas de volatim" (ASSIS, 1975, p. 101), conduz ao seguinte questionamento: o pendor liberal-iluminista para o raciocínio abstrato, livre e 
variado acerca das possibilidades da ação humana, quando desprovido de estofo sentimental e moral, não atinge a felicidade que prevê, ou, como diz Trilling (1953a, p. 8), nega a possibilidade de felicidade.

Em Brás Cubas, "o ridículo de uma ideia fixa atravessada na cabeça" do protagonista - ideia essa que leva, geralmente, à criação de alguma "desenganada teoria do homem", para usar expressões de Eugênio Gomes (1958, p. 57, 175) - induz ao entendimento de que um dos pressupostos do conservadorismo, o ceticismo político, é uma crítica à ambição racionalista da imaginação liberal. Nas palavras de Roberto Campos (1991, p. 13): "[...] os cultores do ceticismo político desconfiam do pensamento e teoria aplicados à vida pública, especialmente quando direcionados para ambiciosas inovações".

As principais teorias articuladas nas Memórias póstumas sugerem uma sátira cética e conservadora dos sistemas políticos e filosóficos voltados à utópica solução ou explicação dos problemas da humanidade. Para ficarmos com o exemplo mais relevante: o Humanitismo de Quincas Borba pode ser paródia do positivismo, como diz Bosi (2006, p. 311), referência ao darwinismo, conforme salienta Reale (2005, p. 26-27), mas também irônica alusão a todas as utopias de igualdade, de felicidade, de reorganização social e econômica da sociedade. Recordemo-nos que Brás, no fim da história, descobre tardiamente o valor do ceticismo, proferindo a Quincas Borba: "- Vai para o diabo com teu Humanitismo [...]; estou farto de filosofias que me não levam a cousa nenhuma." (ASSIS, 1975, p. 282). No dizer de Leandro Konder (2009, p. 107-108): "Machado, [...] sempre inclinado a desconfiar de remédios drásticos, pretensamente capazes de curar do dia para a noite todos os males da sociedade brasileira [...] - é claro - não era socialista.". ${ }^{2}$

Para Roberto Schwarz (2000b, p. 18), a volubilidade do narrador Brás Cubas é, a um só tempo, "regra de composição da narrativa" e "uma conduta própria à classe dominante brasileira". É razoável essa noção de que a volubilidade é tanto o princípio de organização das categorias da narrativa e do discurso narrativo como a fisionomia de dados externos. No entanto, ao invés de esses dados externos serem vistos como aspecto de classe, eles podem ser divisados como tendência intelectualista (primazia do intelecto e da racionalidade abstratos sobre as emoções e os sentimentos) própria à imaginação liberal.

\footnotetext{
${ }^{2}$ Segundo Leandro Konder (2009, p. 107-108), Raimundo Magalhães Júnior descobriu que Machado publicou uma crônica na Gazeta de Notícias, em 13 de janeiro de 1885, em que ironiza o marxismo.
} 


\section{Referências}

ADORNO, Theodor Wiesengrund. O ensaio como forma. In: Notas de literatura I. Trad. Jorge Matos Britto de Almeida. São Paulo: Duas Cidades; Editora 34, 2003a. p. 15-45.

. Palestra sobre lírica e sociedade. In: Notas de literatura I. Trad. Jorge Matos Britto de Almeida. São Paulo: Duas Cidades; Editora 34, 2003b. p. 65-89.

ARANTES, Paulo Eduardo. Sentimento da dialética na experiência intelectual brasileira: dialética e dualidade segundo Antonio Candido e Roberto Schwarz. Rio de Janeiro: Paz e Terra, 1992.

. Conversa com um filósofo zero à esquerda. In: Zero à esquerda. São Paulo: Conrad, 2004. p. 257-298.ASSIS, Machado de. Memórias póstumas de Brás Cubas. Edição crítica da Academia Brasileira de Letras. Rio de Janeiro: Civilização Brasileira; Brasília: Instituto Nacional do Livro, 1975.

BARRETO FILHO. Introdução a Machado de Assis. Rio de Janeiro: Agir, 1947.

BERLIN, Isaiah. Dois conceitos de liberdade. In: Estudos sobre a humanidade: uma antologia de ensaios. São Paulo: Companhia das Letras, 2002. p. 226-272.

BOSI, Alfredo. A escravidão entre dois liberalismos. In: Dialética da colonização. 3. ed. São Paulo: Companhia das Letras, 1996. p. 194-245. Brás Cubas em três versões. Teresa - Revista de Literatura Brasileira, São Paulo, n. 6/7, p. 279-317, 2006.

CAMPOS, Roberto. Prefácio: Merquior, o liberista. In: O liberalismo: antigo e moderno. Trad. Henrique de Araújo Mesquita. 2. ed. Rio de Janeiro: Nova Fronteira, 1991. p. 1-14.

FRANCO, Maria Sylvia de Carvalho. As ideias estão no lugar. Cadernos de Debate 1: História do Brasil, São Paulo, n. 1, p. 61-63, 1976.

GOMES, Eugênio. Machado de Assis. Rio de Janeiro: São José, 1958.

HEGEL, Georg Wilhelm Friedrich. Fenomenologia do espírito. Trad. Paulo Meneses, com a colaboração de Karl-Heinz Efken e José Nogueira Machado. 9. ed. Petrópolis: Vozes; Bragança Paulista: Ed. Universitária São Francisco, 2014.

KONDER, Leandro. A referência de Machado de Assis a Marx. In: A derrota da dialética: a recepção das ideias de Marx no Brasil, até o começo dos anos 30. 2. ed. São Paulo: Expressão Popular, 2009. p. 107-108.

LUKÁCS, György. A polêmica entre Balzac e Sthendal. In: Ensaios sobre literatura. Trad. Luiz Gazzaneo. 2. ed. Rio de Janeiro: Civilização Brasileira, 1968a. p. 123-146. . Narrar ou descrever. In: Ensaios sobre literatura. Trad. Giseh Vianna Konder. 2. ed. Rio de Janeiro: Civilização Brasileira, 1968b. p. 47-99. . Introdução a uma estética marxista: sobre a particularidade como categoria da estética. Trad. Carlos Nelson Coutinho; Leandro Konder. 2. ed. Rio de Janeiro: Civilização Brasileira, 1970. 
O romance como epopeia burguesa. Trad. Letizia Zinia Antunes. Ad hominem, São Paulo, n. 1, p. 87-136, 1999.

. História e consciência de classe: estudos sobre a dialética marxista. Trad. Rodnei Nascimento. São Paulo: Martins Fontes, 2003.

MAYA, Alcides. Machado de Assis: algumas notas sobre o humour. 2. ed. Rio de Janeiro: Academia Brasileira de Letras, 1942.

MERQUIOR, José Guilherme. O liberalismo: antigo e moderno. Trad. Henrique de Araújo Mesquita. Rio de Janeiro: Nova Fronteira, 1991.

MEYER, Augusto. Machado de Assis (1935-1958). Rio de Janeiro: São José, 1958.

PEREIRA, Lúcia Miguel. Machado de Assis: estudo crítico e biográfico. 6. ed. Belo Horizonte: Itatiaia; São Paulo: Edusp, 1988.

REALE, Miguel. A filosofia na obra de Machado de Assis. Revista Brasileira, Rio de Janeiro, n. 44, p. 7-33, 2005.

RICUPERO, Bernardo. Da formação à forma: ainda as "ideias fora do lugar". Lua Nova, São Paulo, n. 73, p. 59-69, 2008.

. O lugar das ideias: Roberto Schwarz e seus críticos. Sociologia Et Antropologia, Rio de Janeiro, v. 3, n. 6, p. 525-556, 2013.

ROUANET, Sergio Paulo. Contribuição para a dialética da volubilidade. Revista USP, São Paulo, n. 9, p. 175-194, 1991.

SCHWARZ, Roberto. O sentido histórico da crueldade em Machado de Assis. Novos Estudos CEBRAP, São Paulo, n. 17, p. 38-44, 1987.

. Um seminário de Marx. Novos Estudos CEBRAP, São Paulo, n. 50, p. 99-114, 1998.

Um mestre na periferia do capitalismo: entrevista. In: Sequências brasileiras: ensaios. São Paulo: Companhia das Letras, 1999. p. 220-226.

Ao vencedor as batatas: forma literária e processo social nos inícios do romance brasileiro. São Paulo: Duas Cidades; Editora 34, 2000a.

Um mestre na periferia do capitalismo: Machado de Assis. São Paulo: Duas Cidades; Editora 34, 2000b.

. Roberto Schwarz - Obra Aberta Machado de Assis 2002 (3 de 4). 2011. 1 vídeo (12min26s). Publicado pelo canal Desisifo. Disponível em: <https://www.youtube.com/watch?v=qmYVXuvMwxg>. Acesso em: 25 jun. 2019.

. Por que "ideias fora do lugar"? In: Martinha versus Lucrécia: ensaios e entrevistas. São Paulo: Companhia das Letras, 2012. p. 165-172.

TRILLING, Lionel. Preface. In: The Liberal Imagination: Essays on Literature and Society. New York: Doubleday, 1953a. p. 5-10.

The Meaning of a Literary Idea. In: The Liberal Imagination: Essays on Literature and Society. New York: Doubleday, 1953b. p. 268-287. 
WEBER, Max. A "objetividade" do conhecimento na ciência social e na ciência política. In: Metodologia das ciências sociais. Trad. Augustin Wernet. 4. ed. São Paulo: Cortez; Editora Unicamp, 2001. p. 107-154.

ELVIS PAULO COUTO é doutorando do Programa de Pós-Graduação em Estudos Literários da Faculdade de Ciências e Letras da UNESP de Araraquara.

@https://orcid.org/0000-0002-2570-3875. E-mail: coutoelvis@yahoo.com.br.

Recebido em: 03.12.2019

Aprovado em: 09.04.2020 